\title{
O Discurso dos Professores Sobre a Formação Continuada em suas Respectivas Áreas do Conhecimento
}

\section{The Teachers 'Speech on Continuing Training in their Respective Areas of Knowledge}

\author{
Janaína Giovana da Silvaa; Cilene Maria Antunes Maciel*a \\ ${ }^{a}$ Universidade de Cuiabá, Programa de Pós-Graduação Stricto Sensu em Ensino. MT, Brasil. \\ *E-mail: cilenemlamaciel@gmail.com
}

\begin{abstract}
Resumo
O estudo teve o objetivo principal de analisar como se desenvolve o programa da formação continuada em quatro escolas estaduais, no município de S. A. L., ressaltando a eficiência e as dificuldades no contexto educacional dessas instituições, bem como os desafios e as perspectivas nos discursos dos professores. Na abordagem qualitativa, utilizando-se da pesquisa de campo como um dos procedimentos, pautada em autores que contribuíram para uma base teoricamente referendada. O procedimento de coleta de dados usado foi a entrevista não padronizada ou semiestruturada com 20 professores e seis coordenadores das referidas escolas. Utilizou-se a análise do discurso, na vertente francesa fundamentada nos estudos do filósofo Michel Pêcheux (1995), com efeito de sentido na linguagem, na sociedade e na história. Buscou-se compreender os desafios presentes nos discursos dos participantes sobre o processo da formação continuada, evidenciando o estudo, a pesquisa e sua aplicabilidade em novas formas metodológicas de desenvolver o trabalho docente.
\end{abstract}

Palavras-chave: Formação Continuada. Professor. Discurso. Desafios.

\begin{abstract}
The study had the main goal of analyzing how the continued education program develops in four state schools, in the municipality of S. A. L., emphasizing the efficiency and difficulties in the educational context of these institutions, as well as the challenges and perspectives in the speeches of the teachers. In the qualitative approach, using field research as one of the procedures, based on authors who contributed to a theoretically endorsed basis. The data collection procedure used was a non-standard or semi-structured interview with 20 teachers and six coordinators from those schools. Discourse analysis was used, in the French perspective based on the studies of the philosopher Michel Pêcheux (1995), with a meaning effect on language, society and history. We sought to understand the challenges present in those speeches of continuined education, highlighting the study, research and its applicability in new methodological ways of developing teaching work.
\end{abstract}

Keywords: Continuing Education. Teacher. Speech. Challenges.

\section{Introdução}

Atualmente, a docência não tem a função meramente de transmissão de conhecimento. Ela, hoje, se realiza na relação, na interação, na convivência, na cultura do contexto, na heterogenidade social dos sujeitos envolvidos no processo (discente, docentes, comunidade, especialistas). Do atual professor, se demanda posturas, comportamentos e diferentes ações: uma nova competência contemporânea para animar, mediar, informar, formar, construir e transformar conhecimentos.

Nessa perspectiva, os professores devem ter a disposição uma formação que lhes proporcione o exercício da reflexão coletiva, que possibilite efetiva participação na análise, na compreensão e na proposição do conteúdo e do processo de seu trabalho. Uma análise crítica e fundamentada que os dote da capacidade de enfrentamento da convivência em tempos de mudança e de incertezas (IMBERNÓN, 2006).

Algumas concepções e finalidades sobre a educação e a formação continuada de professores no Brasil nas últimas décadas, tem mostrado mudanças significativas ao longo do tempo, ligadas diretamente ao contexto histórico, econômico, político e social do país. Evidenciando a importância do preparo desses docentes, constatando que a ideia de treino de habilidades e técnicas foram sendo substituídas pelo entendimento de que a aprendizagem contínua e permanente é primordial no desenvolvimento profissional docente, no empenho de suas funções, na aprendizagem do discente e no envolvimento da sociedade como um todo.

Com as mudanças no conceito das finalidades, novos vocábulos foram sendo utilizados. Andaló (1995) destaca as palavras "treinamento" e "reciclagem" na aquisição de habilidades e conhecimentos atuais. A palavra "treinamento" estava diretamente ligada a aquisição de habilidades específicas, já "reciclagem" direcionava para a preparação de uma nova função a ser realizada.

Com análise dos termos e concepções empregados na temática da formação contínua dos docentes, Marin (1995) percebeu o uso de alguns vocábulos relacionais como: reciclagem, treinamento, aperfeiçoamento, capacitação, educação permanente, educação continuada. Na "reciclagem" ocorria mudanças radicais para o cumprimento de uma nova 
função, direcionando a implantação de cursos de formação continuada rápidos e aleatórios; o "treinamento" voltava-se a capacidade que o sujeito tinha para realizar determinada tarefa através de uma disciplina modeladora do comportamento. $\mathrm{O}$ vocábulo "aperfeiçoamento" consistia em tornar perfeito, completando o que era inacabado, enquanto "capacitação" era tornar o sujeito capaz, isto é, habilitá-lo.

É importante lembrar que esses termos, com os avanços em estudos sobre a temática, foram sendo substituídos gradativamente por outros de significados mais complexos na medida em que a concepção de formação continuada foi adquirindo funções e papéis diversificados, mais abrangentes e totalmente significativos.

A partir dos anos 90, por exemplo, com as mudanças histórico ideológicas que forma marcando a sociedade, a formação continuada de professores foi bastante influenciada por inúmeros debates sobre desenvolvimento profissional e a profissionalização do docente (IMBERNÓN, 2006) formação no contexto escolar; professor-formador (NÓVOA, 1991), professor reflexivo (SCHÖN, 1987, 1992, 1995), professorpesquisador (ZEICHNER, 1998). Destarte, a formação continuada é uma questão bastante abrangente e multifacetada, e intensos debates e estudos têm sido travados em torno das concepções existentes.

A relação teoria, discurso e prática surge nos debates acadêmicos, nas pesquisas, mesmo no cotidiano, como tema contumaz, embora, um olhar mais atento faça perceber que aos conceitos de teoria, discurso e prática nem sempre são atribuídos os mesmos sentidos.

Ao falar da formação de professores em seu sentido amplo, decidiu-se por denominá-la de formação continuada, que exprime de forma total o conceito de construção desse profissional da educação, evidenciando seu discurso, suas ideias e principalmente sua ideologia, posto que no contexto escolar, inúmeros são os agentes envolvidos e, diversos são os fatos inerentes a ela.

Essa formação, entre outros objetivos, propõe numa coletividade que os docentes estudem, pesquisem e apliquem metodologias inovadoras, e que estas estejam em consonância com as necessidades surgidas no contexto da escola e dos discentes, instruindo-os para o mundo social e do trabalho que é hoje, exigência de documentos como a BNCC (Base Nacional Comum Curricular) direcionados ao novo contexto educacional.

Tornar acessível aos profissionais da educação, teorias e práticas atualizadas, com a intenção de privilegiar inovações necessárias para o aprimoramento das ações pedagógicas e, por conseguinte, da educação é o que se anseia. Aprender novas teorias, novas metodologias, e entender-se ator executante delas, contribui muito nesse seguimento para a estruturação desse profissional, porém não basta, se estas não derem ao professor a possibilidade de contrastá-las com a sua práxis (NÓVOA, 1995; PERRENOUD, 2000).
Com isso, a presente pesquisa teve como objetivo principal analisar como acontece a formação continuada nessas escolas do município de S. A. L. Considerando os desafios presentes no discurso e na prática dos professores, sua integração com os pares e o efetivo espaço para autonomia da escola, tendo em vista a produção dos conhecimentos a partir dos estudos voltados para o aprimoramento e aplicabilidade de uma inovada práxis.

$\mathrm{O}$ objetivo desse trabalho, emergem as perguntas norteadoras, voltadas para a problemática investigada: qual o espaço reservado à emancipação e autoria dos profissionais das escolas públicas nos programas de formação continuada? Qual é o tempo destinado à formação continuada, visto como "suficiente" pelo professor? Qual a influência dos programas de formação continuada na prática em sala de aula, no cotidiano do professor? Existe oportunidade para a construção autônoma da prática docente, a partir das suas experiências e pesquisas?

\section{Material e Métodos}

A pesquisa foi realizada na abordagem qualitativa e desenvolvida em quatro escolas públicas do município de $\mathrm{S}$. A. L.-MT. A princípio, elas foram escolhidas por atenderem às modalidades diferenciadas de ensino, três delas localizada na sede e uma situada no distrito de Varginha, denominada de escola do campo, distante mais ou menos da sede, $8 \mathrm{~km}$. Foram entrevistados 26 profissionais da educação, sendo 20 professores e seis coordenadores. Os professores e coordenadores tiveram suas falas gravadas para transcrição e análise posterior, mediante permissão assinada nos termos exigidos para a realização da pesquisa, conforme orientação do Comitê de Ética da Universidade de Cuiabá.

Sobre a pesquisa qualitativa Minayo (2001) aborda questões singulares e, utiliza a significação geral, motivos, desejos, crenças e atitudes que corresponde a um aprofundamento das relações, dos processos e dos fenômenos que podem operacionalizar as variáveis. Mergulha-se nuns conjuntos de significados voltados para a humanidade, cujo sentido não é percebido nem captado de forma estatística e exata.

Nesse ponto, detalha-se os caminhos percorridos durante a pesquisa, com informações inerentes a cada procedimento realizado, desde a primeira visita as escolas, as conversas com as gestoras e a anuência das mesmas para que a pesquisa pudesse ser realizada no interior das instituições, a observação in lócus, analisando ações e interação ocorridas no contexto de cada uma, juntamente como os sujeitos envolvidos no processo.

Com relação as conversas com as diretoras das escolas, predominando na função, mulheres, observou-se preocupação no que se refere a divulgação do que acontece no interior dessas instituições. Todas questionaram se haveria exposição do que fosse constatado com o estudo, porém foi explicado 
que, o sigilo era imprescindível no processo, que o objetivo das pesquisadoras é entender o programa da formação continuada e sua execução no interior das instituições, bem como o comportamento do professor e coordenador no desenvolvimento desse trabalho.

De natureza aplicada, a pesquisa buscou o progresso da ciência e os conceitos relacionados ao fenômeno analisado sobre o processo da formação continuada de professores no município de S. A. L.-MT e a sua influência no contexto social dos indivíduos participantes. Se preocupou em aplicar os conceitos estabelecidos por meio de estudos bibliográficos e práticos do tema em estudo, bem com realizar uma análise criteriosa dos dados coletados.

Empenhou-se em construir diagnósticos nas observações dos ambientes, das relações entre os sujeitos e das entrevistas não padronizadas (semiestruturadas) (MARCONI; LAKATOS, 2017), a identificar problemas que interferem e dificultam a realização do processo e apontar possíveis propostas para minimizar os desafios que surgem no decorrer do trabalho docente. Abrange questões criadas pelos sujeitos e suas instituições (THIOLLENT, 2009).

O lócus da pesquisa constituiu-se de 4 escolas estaduais que aqui usou-se denominações fictícias para indicar as mesmas. Escola 1- Monteiro Lobato (atende anos iniciais do Ensino fundamental-EF); Escola 2 - Cecília Meireles (atende o EF do $1^{\circ}$ ao $9^{\circ}$ anos); Escola 3 - Clarice Lispector (Atende anos finais do EF, o Ensino Médio e A EJA) e Escola 4 - Fernando Pessoa (escola do campo- atende EF e Médio da localidade). Essas escolas foram escolhidas pelas pesquisadoras por variarem sua forma de desenvolver a tarefa de transmissão, mediação e construção de conhecimentos.

Os sujeitos da pesquisa foram professores das diversas áreas do conhecimento; efetivos e contratados. Sendo cinco profissionais de cada escola citada acima, de diferentes áreas do conhecimento, incluindo a Unidocência; e os coordenadores pedagógicos 6 (seis) das referidas instituições que participaram de forma ativa no processo, mediante assinatura dos termos de consentimento (TCLE) e termo de uso de som e imagem.

Ainda se utilizou a observação participativa do ambiente e as entrevistas não padronizadas (MARCONI; LAKATOS,2017) que foram realizadas de forma individual com os participantes que concordarem em contribuir com os estudos sobre o fenômeno abordado. A pesquisa estimulou a compreensão do objeto em estudo.

Nesse caso, as pesquisadoras optaram por uma observação participante cujo o objetivo foi estar junto aos sujeitos da pesquisa, apreciando o contexto, os comportamentos, as opiniões e a forma como eram conduzidos os encontros para estudo dessa formação continuada pelos coordenadores, para então, percorrer de forma gradativa os procedimentos da pesquisa, respeitando as etapas a serem construídas e os pontos de vistas das pessoas constituíram o escopo do estudo.

Considerando o contexto e os tipos de sujeitos envolvidos na pesquisa, optou-se por utilizar como instrumento de coleta de dados, também a técnica da entrevista não padronizada ou semiestruturada, pois sua flexibilidade oportunizou uma investigação detalhada sobre o tema, salientando os saberes dos entrevistados, seus pensamentos, sentimentos, crenças, desejos, histórias, ideologias e pretensões a respeito da temática em discussão, bem como os esclarecimentos sobre coisas precedentes.

As entrevistas realizadas seguiram um roteiro, considerando a especificidade de cada função dentro da escola. Elaborou-se um roteiro de entrevistas para o professor, no qual indagou-se sobre tempo de exercício no magistério, se realiza alguma formação continuada. Se realiza, onde, quando e como a realiza e se ela atende as necessidades e anseios da profissão. Questionou-se também se a maneira como a formação acontece contribui para uma reflexão mais aprofundada da prática docente em sala de aula, como são escolhidos os temas para estudo? Foi perguntado ainda se a coordenação pedagógica auxilia o trabalho do professor frente as dificuldades apresentadas no decorrer do trabalho docente e que fatores interferem no processo de aprendizagem dos alunos. Finalmente, indagou-se sobre os desafios encontrados durante a formação continuada e qual seria a formação ideal para uma formação continuada realmente satisfatória.

Nas entrevistas com os coordenadores, também se seguiu um roteiro prévio, com estabelecimentos de algumas questões pontuais da investigação. A princípio solicitou-se que cada um relatasse sobre a experiência na coordenação pedagógica da escola, seu tempo no exercício do magistério, como a escola propõe a formação continuada aos professores e como é cobrada a participação e envolvimento deles. Em seguida, inquiriu-se sobre as atividades realizadas pelo coordenador na execução dessa formação continuada no contexto escolar e que dificuldades eles encontravam junto aos profissionais, ao propor tal estudo. Perguntou-se como as temáticas eram escolhidas e se elas eram realmente trabalhadas para sanar os desafios de aprendizagem dos alunos, isto é, como eram desenvolvidas as intervenções pedagógicas.

Solicitou-se ainda que os coordenadores fizessem apontamentos sobre a formação continuada oferecida pelo governo e os envolvimentos dos professores nesse processo. E para finalizar, indagou-se sobre qual seria a formação continuada ideal para atender as necessidades da escola.

Para a análise criteriosa dos discursos obtidos nas entrevistas dos professores e dos coordenadores, utilizou-se do método de análise do discurso, na linha francesa, voltadas para as vertentes da ideologia, do materialismo histórico e da psicanálise (LACAN, 1998).

\section{Resultados e Discussão}

A partir desse momento, será explicitado um pouco do histórico da Análise do Discurso (AD) para posterior entendimento do seja o sujeito do discurso, o seu assujeitamento diante do materialismo histórico presente nos discursos e 
interdiscursos dos sujeitos, participantes dessa pesquisa, considerando que os professores e os coordenadores narram sobre determinado lugar de sua história, de sua vivência, de sua experiência e de sua relação com os outros sujeitos.

Continuamente aos estudos da $\mathrm{AD}$, as noções que aparecem estão distantes de ser um simples discurso político ou até mesmo discurso-doutrina-sermão. Nesse trajeto, há similaridade em entender que as diversas linguagens são ou podem ser consideradas discursos, assim, ao relacionar-se com os diferentes tipos do ser docente atualmente, e suas múltiplas facetas, a ideia que surge é que existe aí uma perda significativa do discurso educacional no contexto da formação inicial e continuada, justamente no ápice solidificado do capitalismo pelo neoliberalismo.

O importante aqui é chamar a atenção para a ideologia colocada em voga por esse sistema numa linha discursiva, todavia, é necessário ter aportes para entender claramente os pontos da $\mathrm{AD}$ e suas nuances.

Seu contexto histórico se origina da França, haja vista alguns conceitos de formação discursiva serem já empregados por Foucault, em sua concepção discursiva como partículas empiristas, que se idealiza num todo discursivo, em um composto de absolvição a outros dizeres e a locução discursiva. Sem que haja uma inversão das teorias Marxista nem foucaultina. Pêcheux (1995) associou as relações dialógicas com os métodos de captação, pelos indivíduos e suas relações de criação e a ideologias concebidas sobre o materialismo histórico. Proclama-se que a AD é um saber que trabalha especialmente com a geração de sentidos.

Desse modo, optou-se pelo uso da AD neste trabalho na perspectiva de que Michel Pêcheux, ao detalhar o funcionamento linguístico textual dos discursos das categorias diferenciadas ao emprego da língua, percebeu que ela se idealiza por um estabelecido ambiente histórico da criação. Perante este panorama, o estilo linguístico do analista do discurso varia do estilo do linguista, por diversos motivos, entre eles o comportamento em si (enquanto todo) o não todo unido a definição do factual da língua, o que a faz única na criação de ambiguidade. (FERREIRA 2003)

No escopo da pesquisa, o universo dos participantes analisado se compôs 26 sujeitos, sendo 12 professoras oito professores. Na função da coordenação pedagógica tem-se seis participantes, cinco coordenadores e umacoordenadora.

Esses participantes se dividem nas diferentes áreas do conhecimento, as quais: Humanas, Linguagens e suas tecnologias, Matemática, Ciências e a Unidocência. Nos variados componentes curriculares, dando a possiblidade de uma investigação detalhada e complexa sobre o objeto pesquisado, no espaço educacional.

Nesse ponto, ao analisar os discursos dos professores sobre a formação continuada no contexto da escola, todos foram unânimes em afirmar que participam da formação continuada oferta pela escola, como política pública do Estado. Nesse momento, para identificar os participantes na pesquisa, usou- se a abreviação $\mathrm{P}=$ Professor e a numeração de 01 a 20 para especificar os discursos, sem nomear o sujeito falante.

Assim, nesse primeiro momento, escolheu-se analisar os dizeres dos professores sobre a participação e o envolvimento no programa da formação continuada (FC), devido a ser uma das questões indaga pelo entrevistador aos entrevistados: Nos discursos a seguir, observa-se as premissas discursivas de alguns docentes.

Bom, eu participo da única que é oferecida pela escola que é o PEFE, diz que somos obrigados como efetivos a participar dessa formação, então é por isso que eu participo pois, de certa forma é obrigado a participar. (P 07)

Participo sim, porque a formação é uma forma da gente crescer e é algo que querendo ou não é obrigatório mesmo não sendo tema bom, hum. (P 01)

Primeiro com o anseio de estar buscando e aperfeiçoando mais para a prática pedagógica. Eu participo de todas, tudo que vem a falar que é para informação, que é para adquirir mais conhecimento e que vem para o benefício tanto meu quanto do aluno, participo de todas. (P 02)

Sim, na sala do educador oferecida pela escola cm supervisão do Cefapro. (P 03)

Sim, somente a formação ofertada pelo Cefapro dentro da escola. (P 20)

Ao analisar os discursos empregados pelo professor quanto sua participação na FC nota-se que por ela ser a única ofertada pela escola, como política pública do Estado, o professor deve cumpri-la com parte de sua carga horária semanal, todavia, dentro das escolas investigadas não é $100 \%$ do corpo docente que cumpre esta normativa. A porcentagem de não participantes varia de escola para escola, entre $25 \%$. No entanto, em duas instituições pesquisada, pode-se constatar que há uma totalidade no envolvimento e participação dos professores.

Acomposição curricular e a transmissão dos conhecimentos da língua e da linguagem nesse processo, deixa nítido o domínio do discurso entendido como sistema estruturado e normativo a ser seguido. Constatações que, lamentavelmente habitam o ilusório coletivo social, nela inclusos estudiosos, cientistas, pesquisadores, professores e professoras de forma geral.

Em síntese, Foucault (1996) afirma que sobre a ordem do discurso, é dito que o coletivo de práticas discursivas dos professores apregoa-se na idealização da função que as instituições escolares têm que é administrar de forma clara e objetiva os conteúdos, frequentemente empregados na norma padrão, e esta ordenação do discurso é decisória na escolha de como se ensinar e o que se ensinar.

Dessa maneira, deve-se ter claro que a enunciação, conjunto de normas, independente da sua individual produção, se relaciona intensamente com a comunidade de falantes a qual se pertence, pois trata-se de um episódio social, unido fortemente ao seguimento histórico de conjunto de emissores dada a crescente evolução desse discurso, salientando que todo dialeto, linguajar tem sua história.

A formação continuada não deve ser apontada como 
produto único e determinante da boa ou má atuação do professor, pois é sabido que em decorrências dos momentos históricos, a escola passou a ter diversas funções que a fez ganhar ares mais burocráticos, valorados e importantes, e os processos de ensinagem e aprendizagem passaram a ser essenciais no desenvolvimento do trabalho educativo.

Fica evidente que ao professor cabe o papel de realmente entender-se no processo dessa formação continuada como protagonista do seu próprio conhecimento, contribuindo para o crescimento mútuo dele, dos colegas e, principalmente dos alunos, acreditando-se possuidor de um discurso rico de credibilidade. O que corroboram Pimenta (1999), Tardif (2014) e Imbernón (2006) que defendem a formação continuada de professores como necessidade indubitável no contexto escolar, criando momentos de reflexão, de construções de saberes e possibilidades variadas de empregar, em sua totalidade, os conhecimentos adquiros por intermedio dos estudos e das pesquisas realizadas.

Essa formação, entre outros objetivos, propõe metodologias inovadoras, informando os profissionais sobre teorias e práticas atuais, com o intuito de privilegiar mudanças necessárias para o aprimoramento das ações pedagógicas na escola e, por conseguinte da educação. É evidente que aprender novas teorias, contribui no processo de construção desse profissional, porém não é o suficiente se estas não dão ao professor possiblidade de confrontá-las com a sua prática diária (NÓVOA, 1995; PERRENOUD, 2000).

Ainda neste ponto, pode-se analisar a proposição da professora (6), em seu discurso quando ela diz:

Olha, eu vejo o seguinte, às vezes eu prefiro estar em casa lendo um livro, fazendo outra atividade do que estar participando. (P 16)

Nota-se nesse discurso que essa profissional tem a FC como algo não tão significativo na questão da aprendizagem quando ela diz "[...] eu prefiro estar em casa lendo um livro, fazendo outra atividade[...]". O não dito aqui implícito nesse discurso pode ser pensado por diversas óticas, passando pelo não planejamento das ações pelo formador, a falta de organização do tempo e espaço e até as temáticas nada relacionadas às áreas de conhecimentos aplicadas pela escola e necessárias ao educador.

As imposições educacionais, mesmo diferenciadas em suas finalidades, são reforçadas pelas entidades e profissionais que querem a qualidade social da educação, usufruindo de todas as oportunidades oferecidas para a realização da um trabalho complexo e sistêmico que é a função do professor, esse agente deve estar disponível para aprender, para construir seus diversos saberes (TARDIF, 2014).

Com as mudanças diárias no contexto social, histórico, tecnológico, científico e na modernidade dos meios de comunicação, novos paradigmas, hoje mais que em outros tempos, são imprescindíveis para garantir uma ressignificação no desempenho do profissional nas mais diversas áreas. Não cabe mais ao profissional achar que porque terminou sua formação escolar inicial, já sabe tudo e está pronto para atuar profissionalmente na sociedade.

A vida muda, os contextos mudam, tudo se transforma, por isso, é justo que a formação continuada seja realmente contínua e significativa e, que esse professor se entenda núcleo principal desse processo.

No tocante a significação da formação continuada constata-se que ela se idealiza num contexto de geração de novos saberes, de socialização de saberes diversificados, de reconsiderar e reconstruir a práxis do professor, respeitando a aquisição das suas competências e habilidades no âmbito educacional. Admitindo a construção do preponderante no ponto de vista do convívio e da interveção na composição do profissional professor (VYGOTSKY, 1994).

Ainda, no tocante a categoria: participação na FC, observase nesses outros discursos:

Eu participo, porque está dentro da atribuição do professor. (P 13)

Eu participo, pois faz parte do meu perfil e é um dos prérequisitos para sermos avaliados e atribuir aula no ano seguinte. Na verdade, pela cobrança. (P 12)

No primeiro discurso, o professor aborda a materialidade histórica da profissão. De certa forma, ele sabe que é função do professor formar-se, estudar, pesquisar, adquirir saberes essenciais para o cumprimento do dever, atribuido qualidade ao propósito educativo que lhe imposto.

No segundo discurso, o professor deixa explicito a cobrança que ocorre ao se decidir por essa profissão, pois ele é responsavel por transmitir/mediar conhecimentos, persuardir os alunos da importância do estudo, integrar-se ao coletivo, trocar experiências, entre outras competências que são inerentes a profissão. Deixa claro que há condicionantes que não o permite ter a garantia do exercício da função no ano seguinte, pois apesar de fazer parte do perfil dele, é a cobranca que o motiva a participar da FC na escola.

Michel Pêcheux (1995) ponderou que o sujeito expõe sua fala de diferentes localizações sociais e que essa construção discursiva é diretamente impactada por antagônicos posicionamentos que integram as variedades da relação indivíduo universal com o indivíduo da comunicação, do indivíduo da fala com o indivíduo da caracterização.

A existência do enunciado é da ordem de uma materialidade repetível que se dirige, segundo uma dimensão, de algum modo vertical, às condições de existência dos diferentes conjuntos significantes. (COURTINE, 2009, p.141).

O conceito de materialismo foi ampliado, difundindo ao conceito de divergência social, parametrizando a ideologia materializada em variadas entidades e realizações sociais e confirmou que "o mecanismo pelo qual a ideologia leva o agente social a reconhecer o seu lugar é o mecanismo da sujeição social [...] é um mecanismo com duplo efeito: “[...] o agente se reconhece como sujeito e se assujeita a um sujeito absoluto". (ALTHUSSER, 2001, p.8) 
O materialismo da existência se concretiza pela materialidade histórica, pois é no íntimo dos aparelhos estatais que acontecem as interações de produção, hegemonia, submissão e incoerência. Sendo as convicções objeto significativo do discurso, já que é parte integrante dos dispositivos de produção e criação.

O sistema ideológico, isto é, o instrumento das convicções é produzido no interior da vivência social, assegurando a aparência de liberdade, apregoando-os na condição de sujeito, inovando das formações ideológicas, que de forma desigual pode conceber e modificar valores antes não existentes.

Althusser conduz Pêcheux (1992), ao entendimento de que no interior das instituições pode ocorrer a conservação das relações de criação, por entre modelos metafóricos de sua interação com a concretude real, pois a ideologia está no e ultrapassa o sujeito. Ele evidencia a nitidez da linguagem e a consequência das convicções. É Pêcheux que faz a ligação, inserindo o discurso no contexto da historicidade do sujeito.

\section{Conclusão}

Foi necessário algum conhecimento prévio sobre a $\mathrm{AD}$ no tocante a instabilidade da materialidade da linguagem. Nesse ponto, a AD incorpora-se como disciplina em constante construção, agravante da linguística, devido ao convívio com outros conceitos que integram a teoria discursiva como o sujeito, a história, a ideologia, o sentido e o próprio discurso, que surpreende pelos sentidos e pela ingenuidade com a realidade.

Com isso, a análise do discurso se propõe a fazer leituras críticas, complexas e reflexivas, não puramente linguísticas nem tão pouco dissolvidas num trabalho histórico referente ao regime das verdades absolutas. Ela se operacionaliza com o significado das convicções que engloba, inicialmente a contradição que está sustentando as relações dos diferentes grupos sociais, cuja as ideias são confrontadas, numa correspondência de forças; levando em conta a concepção de interpretação/assujeitamento e dos mecanismos ideológicos do estado que administram e legitimam as relações.

Com as transformações instantâneas, sejam elas no âmbito da sociedade, da tecnologia, da ciência e no avanço dos meios de comunicação nessa era digital, nos rumos se tornaram fundamentais para assegurar um significado amplo e substanciado nas mais diversas atividades profissionais das diferenciadas áreas. É impossível, atualmente, o docente achar que porque tem uma graduação, já ser detentor absoluto do saber e está altamente capacitado para realizar seu trabalho na sociedade, sem nenhuma interferência.

Destarte, transparece que ao professor, fica a incumbência de compreender-se no desenvolver dessa formação continuada como personagem principal na construção de seus próprios saberes, cooperando para a melhoria mútua de si e dos colegas e, especialmente dos educandos, crendo-se possuidor de um discurso poderoso e amplo em credibilidade e ações.

Assim, a AD objetiva surpreender as formas de percepção do seu materialismo linguístico, no exato tempo em que esse entendimento acontece, isto é, em que o sentido se faz realmente sentido. Não esquecendo que o exterior social não é fixo. O sujeito é disperso e cheios de ideias, e estes ideias se materializam nos dizeres e, esses dizeres se materializa na língua.

Percebe-se que a $\mathrm{AD}$ oferece possibilidades de aprofundamento nos significados dos discursos, interpretando os sentidos, estabilizando-os. Desta forma, cabe ao professor ser o analista, percebendo a todo instantes as várias produções discursivas e os deslizes criados pela história.

Após as várias leituras e entendendo a necessidade de maior aprofundamento nesse conteúdo, é possível afirmar que a linguagem é paradoxalmente transformada na $\mathrm{AD}$, a linguagem não modifica; não se cria sentidos quando se articula uma análise do discurso a outra; a AD destrói um discurso, mas também o constrói; percorre um trajeto metodológico para ser correto e, finalmente a linguagem relaciona-se com a poderosa materialidade dos sentidos da língua.

\section{Referências}

ALTHUSSER, L. Aparelhos ideológicos do Estado. Rio de Janeiro: Graal, 2001.

ANDALÓ, C.S.A. Fala, professora: repensando o aperfeiçoamento docente: Petrópolis: Vozes, 1995.

COURTINE, J.J. Análise do discurso político? O discurso Comunista endereçado aos Cristões. São Carlos: EdUFCar, 2009.

FOUCAULT, M. A ordem do discurso. São Paulo: Loyola, 1996.

IMBERNÓN, F. Formação docente e profissional: formar-se para a mudança e incerteza. São Paulo: Cortez, 2006.

LACAN, J. Função e campo da fala e da linguagem em psicanálise. Escritos. Rio de Janeiro: Jorge Zahar, 1998.

MARCONI, M.A.; LAKATOS, E.M. Fundamentos de metodologia científica. São Paulo: Atlas, 2017.

MARIN, A.J. Educação continuada: introdução a uma análise de termos e concepções. Campinas: Papirus, 1995.

MINAYO, M.C.S. (Org.). Pesquisa social: teoria, método e criatividade. Rio de Janeiro. 2001.

NÓVOA, A. Concepções e práticas de formação contínua de professores. Aveiro: Universidade de Aveiro, 1991.

NÓVOA, A. Formação de professores e profissão docente. In: NÓVOA, A. Os professores e a sua formação. Lisboa: Dom Quixote, 1995. p.13-33.

PÊCHEUX, M. A análise de discurso: três épocas (1983). In: GADET, F.; HAK, T. Por uma análise automática do discurso: uma introdução à obra de Michel Pêcheux. Campinas: UNICAMP, 1997.

PÊCHEUX, M. Semântica e discurso: uma crítica à afirmação do óbvio. Campinas: Unicamp, 1995.

PERRENOUD, P. Práticas pedagógicas, profissão docente e formação: perspectivas sociológicas. Lisboa: Dom Quixote, 2000.

PIMENTA, S.G. Formação de professores: identidade e saberes da docência. São Paulo: Cortez, 1999.

SCHÖN, D.A. Formar professores como profissionais reflexivos. 
In: NÓVOA, A. (Coord.). Os professores e sua formação. Lisboa: Dom Quixote, 1992.

SCHÖN, D. A. Educating the reflective practitioner: toward a new design for teaching and learning in the professions. New York: Basic Books, 1987.

SCHÖN, D. Educando o profissional reflexivo: um novo design para o ensino e a aprendizagem. Porto Alegre: Artmed, 2000.

TARDIF, M. Saberes docentes e formação profissional.
Petrópolis: Vozes, 2014.

THIOLLENT, M. Metodologia da pesquisa-ação. São Paulo: Cortez, 2009.

VYGOTSKY, L.S. A formação social da mente. São Paulo: Martins Fontes, 1994.

ZEICHNER, K.M. A formação reflexiva de professores: ideias e práticas. Lisboa: Educa, 1998. 